\title{
Comparative effects of lindane and deltamethrin on mortality, growth, and cellulase activity in earthworms (Eisenia fetida)
}

\author{
Yajuan Shi ${ }^{\mathrm{a}, *}$, Yajing Shi ${ }^{\mathrm{b}}$, Xin Wang ${ }^{\mathrm{c}}$, Yonglong Lu ${ }^{\mathrm{a}}$, Shifa Yan ${ }^{\mathrm{b}}$ \\ ${ }^{a}$ Research Center for Eco-Environmental Sciences, Chinese Academy of Sciences, Beijing 100085, China \\ ${ }^{\mathrm{b}}$ Department of Bio-chemistry Engineering, Liaoning Institute of Science and Technology, Benxi, Liaoning 117022, China \\ c China National Environmental Monitoring Centre, Beijing 100029, China
}

Received 16 June 2006; accepted 20 February 2007

Available online 7 March 2007

\begin{abstract}
Laboratory tests were conducted to compare the effects of various concentrations of lindane and deltamethrin on mature earthworms (Eisenia fetida) cultured in artificial soil during typical acute (14d) and subchronic (42d) exposure periods. The effects of the two pesticides on earthworm mortality, growth inhibition, and cellulase activity were determined for different exposure durations. The toxicity order for earthworm mortality from the 14-day exposure was lindane $>$ deltamethrin, with median lethal concentrations $\left(\mathrm{LC}_{50}\right)$ of 162.1 and $432.9 \mathrm{mg} \mathrm{kg}^{-1}$, respectively. Earthworms exposed to deltamethrin showed dose-dependent toxic effects on growth and cellulase activity only from the acute exposures, whereas lindane's effects on these activities were seen correlated with both the acute and subchronic doses. Also, changes in biomass and cellulase activity during the subchronic exposure period appear to be a more sensitive parameter than the $\mathrm{LC}_{50}$ value in assessing pesticidal injury.
\end{abstract}

(C) 2007 Elsevier Inc. All rights reserved.

Keywords: Persistent organic pollutants (POPs); Deltamethrin; Lindane; Dose-response relationship; Eco-toxicology

\section{Introduction}

Lindane $(\gamma-\mathrm{HCH})$ is an organochlorine insecticide that has been extensively used worldwide. Scientific evidences revealed that lindane possessed the same chemical characteristics (persistence, bioaccumulation, toxicity and longrange transportability) as the dirty dozen initially listed in the Stockholm Convention, posed a risk to public health and the environment, and should be added as new target for global elimination. As a result, lindane use has been restricted or banned in some countries.

Deltamethrin is a pyrethroid insecticide that kills insects on contact and through ingestion. It has very broad spectrum control and has been considered the most powerful of the synthetic pyrethroids [1].

\footnotetext{
* Corresponding author. Fax: +86 1062918177.

E-mail address: yajuanshi@rcees.ac.cn (Y. Shi).
}

Deltamethrin has been recommended as alternative to organochlorine POPs due to its higher efficiency and relatively shorter life in soil, however, it should be selected as a successful alternative only if an acceptable level of risk to non-target organisms can be demonstrated.

To analyze and predict the potential risks of pollutants, one of the most effective approaches is to compare the observed or predicted exposure concentrations with some thresholds for adverse effects on earthworms.

Earthworms are particularly important soil macroinvertebrates, and are often used in assessing the general impact of heavy metal and pesticide pollution in soil [24]. Macro-invertebrates have the ability to preserve and contribute to the overall productivity of the soil ecosystem by maintaining soil structure and by regulating the turnover of organic matter [5]. Earthworms feed, cast, and burrow in soil and are exposed to soil contaminants via their intestine or skin [6]. It is also easy to quantify different life-cycle parameters of earthworms, such as growth and 
reproduction, accumulation and excretion of pollutants, and biochemical responses [7].

Although the toxicity of pesticides on earthworms in contaminated soil has been evaluated from a variety of points of view, such as avoidance, survival, growth, reproduction and protein content [8-11], the responses of the test organisms to subchronic exposure have not been fully investigated. These responses, often referred to as early warning signals, could in fact provide important information in assessing the ecotoxicological risk of pollutants.

The activities of enzymes, such as oxidoreductases (e.g. superoxide dismutase, catalase), transferases (glutathione S-transferases), hydrolases (e.g. acetylcholine esterase) in earthworms are regarded as fast and prognostic indices of individual reaction to the environmental stress [12-15]. Although cellulase has been one of the most commonly studied digestive enzymes, as it is particularly important in the degradation of organic matter $[16,17]$, there are limited ecotoxicological data on cellulase activity available [18].

In this study, acute and subchronic toxicity tests were conducted to compare the effects of lindane and deltamethrin on mortality, biomass, and cellulase activity in mature earthworms (Eisenia fetida). The purpose was to get a more comprehensive understanding of the effects of the two pesticides on earthworms and to provide more information about the potential ecological risk of chemicals on the soil ecosystem. The information obtained from this study is considered critical, as it will provide a foundation for risk assessment.

\section{Materials and methods}

\subsection{Earthworms and pesticides}

Mature Earthworms (E. fetida) of 3 months old with a well-developed clitellum were obtained from the laboratory stock of the China Agricultural University. They were removed from the soil $24 \mathrm{~h}$ before use and stored in Petri dishes on damp filter paper (in the dark at $14 \pm 1^{\circ} \mathrm{C}$ ) to void their gut contents.

The lindane ( $99 \%$ purity) used in this study was produced at the Tianjin Bohai Chemical Plant, China. The deltamethrin $(95 \%$ purity) was produced at the Huayang Pesticide Company, China.

\subsection{Acute toxicological tests}

Earthworms were cultured by standard methods [2] in an artificial soil mixture of sand, sphagnum peat, kaolinite clay, and calcium carbonate. Soil moisture contents were adjusted to $35 \%$ of the basic substrate's dry weight by adding deionized water. The pesticides were dissolved with $2 \mathrm{ml}$ acetone and thoroughly mixed into the artificial soil at concentrations of $20,50,80,120$, and $150 \mathrm{mg} \mathrm{kg}^{-1}$ dry soil for lindane and $5,25,50,100$, and $150 \mathrm{mg} \mathrm{kg}^{-1}$ dry soil for deltamethrin. For the purpose of determining the $\mathrm{LC}_{50}$ values, additional treatments with higher concentration levels (500 and $1000 \mathrm{mg} \mathrm{kg}^{-1}$ dry soil) for both lindane and deltamethrin were also applied. Additionally a positive control was carried out using $2 \mathrm{ml}$ of acetone. The earthworms were introduced into the containers which have been allowed to evaporate for a minimum of $1 \mathrm{~h}$ in an exhaust hood to ensure that the acetone had completely evaporated.

Three replicates were used for each dose. Each of these was a glass container with 10 adult worms in $750 \mathrm{~g}$ of wet artificial soil. The containers were kept in an incubation chamber $\left(20 \pm 1{ }^{\circ} \mathrm{C}, 70-90 \%\right.$ relative humidity with continuous illumination at $400-8001 \mathrm{x}$ ) throughout the test period.

During the test period earthworms were separated from the test substrate, counted, cleaned with deionized water, and weighed on days 3, 7, 10, and 14. All the replicates were examined on each sampling date and the worms then replaced in the containers. Two earthworms were selected from each container to determine cellulase activity at the end of the acute test period (i.e., at day 14).

\subsection{Subchronic toxicological tests}

For the subchronic toxicity tests, lindane was applied at $1,10,20$, and $50 \mathrm{mg} \mathrm{kg}^{-1}$ dry soil; corresponding to its recommended agricultural dose, 10, 20, and 50 fold dosage levels, respectively. Deltamethrin at 5, 25, and $50 \mathrm{mg} \mathrm{kg}^{-1}$ dry soil, corresponding to its recommended agricultural dose, 5 and 10 fold dosage levels. During the first 14 days, the earthworms were cultured using the same procedure as for the acute toxicity tests (Section 2.2). From days 15 to 42, additional food (finely ground and dried cattle dung) was added once a week to every replicate (treatment plus control). Earthworms were fed by applying about $0.5 \mathrm{~g}$ cow dung per worm to the soil surface once a week [19]. The same procedure but with acetone was used as control solvent. After the incubation periods of 28 and 42 days, the earthworms were removed from the substrate, counted, and weighed. Cellulase activity was determined only at the end of the subchronic test period (day 42).

\subsection{Mortality and growth inhibition of earthworms}

The mortality was determined by counting the number of dead earthworms. Earthworms were considered dead if they lacked movement and did not respond to a definite tactile stimulus to the anterior end. Because earthworms tend to disintegrate quickly after death, they were considered to have died if they were missing. $\mathrm{LC}_{50}$ values were computed using Probit Regression modeling for the mortality data.

The weights of earthworms in each dose group reported from the various exposure periods were then used to compute the growth inhibition as follows: 
$\mathrm{GI}_{n}=\frac{\left(W_{0}-W_{t}\right)}{W_{0}} \times 100 \%$,

where $\mathrm{GI}_{n}$ is the growth inhibition for dose group $n, W_{0}$ is the weight on day 0 and $W_{t}$ is the weight after $t$ days of exposure.

\subsection{Cellulase activity}

Two earthworms from each container were taken at days 14 and 42, placed on filter paper (moistened with deionized water) for $4 \mathrm{~h}$ to allow egestion of gut contents, weighed, and homogenized with ice-cold deionized water. The homogenates were centrifuged for $10 \mathrm{~min}$ at $2500 \mathrm{rpm}$, with the supernatants recentrifuged for $5 \mathrm{~min}$ at $3000 \mathrm{rpm}$. The homogenates combined from the two centrifugations were stored at $0-4{ }^{\circ} \mathrm{C}$ until the enzymes were assayed [20].

Cellulase activity was determined using a carboxymethylcellulose (CMC) assay [21], in which $1 \mathrm{ml}$ of CMC- $\mathrm{NaCl}$ and $0.5 \mathrm{ml}$ of the centrifuged homogenate were incubated at $50{ }^{\circ} \mathrm{C}$ for $0.5 \mathrm{~h}$. The reducing-sugar concentration was estimated by use of the DNS (3,5-dinitrosalicylic acid) reagent with a spectrophotometer, with glucose used as the standard for reducing-sugars [22]. Enzymatic activity was expressed as milligram glucose released per milligram of protein per hour. The protein content of the body tissue homogenate was determined according to Lowry et al. (1951) using bovine serum albumin as a standard [23].

\subsection{Statistical analysis}

The data for growth inhibition and for cellulase activity were each subjected to a one-way analysis of variance (ANOVA) using the Student-Newman-Keuls ( $\mathrm{S}-\mathrm{N}-\mathrm{K}$ ) post hoc pairwise multiple comparison procedure for contrast of the differences among treatment means. The Shapiro-Wilk test and Levene's test were used to ensure the normality assumption and the homogeneity of variances, respectively. Logarithmic transformation was applied to the dependent variables where necessary. Where the variable could not present normality and homoscedasticity even after transformation, the non-parametric KruskalWallis $H$ test was used instead to compare the treatment means. The results were expressed as means $\pm \mathrm{SD}$. Results with $P<0.05$ were considered significant with all statistical significance. All statistics were performed using the SPSS ${ }^{\circledR}$ software (SPSS ${ }^{@}$ Inc., 1999).

\section{Results}

\subsection{Mortality}

The $\mathrm{LC}_{50}$ values, which are the most widely used acute toxicity indicator, were calculated in this study to compare the acute lethal effects of lindane and deltamethrin separately on earthworms. The acute toxicity of lindane to earthworms after $14 \mathrm{~d}$ exposure was higher than the toxicity of deltamethrin, with median lethal concentrations $\left(\mathrm{LC}_{50}\right)$ of 162.1 and $432.9 \mathrm{mg} \mathrm{kg}^{-1}$, respectively.

Mortality levels were lower than $12 \%$ after exposure to lindane $\left(0,1,10,20\right.$, and $\left.50 \mathrm{mg} \mathrm{kg}^{-1}\right)$ and deltamethrin $\left(0,5,25\right.$, and $\left.50 \mathrm{mg} \mathrm{kg}^{-1}\right)$ for 28 and 42 days.

\subsection{Growth inhibition}

\subsubsection{Acute toxicity on growth}

The growth inhibition of earthworms at 3, 7, 10, and 14 days for the two pesticides are shown in Figs. 1a and b. Under the experimental conditions used here, the growth inhibition for the controls was negative, with the biomass increasing during the 14-day exposure period. The mean biomass of the individual worms also increased from 0.206 to $0.218 \mathrm{~g}$ after 14 days of exposure.

Growth inhibition of earthworms exposed to lindanetreated soil were significantly (Fig. 1a) higher than those of the controls. The decrease in weight was shown to be dose-dependent over the 14-day exposure period. This was confirmed by both the one-way ANOVA and the non-parametric Kruskal-Wallis $H$ test (ANOVA, $P<0.01$ for the 3-day, 7-day and 10-day exposure; and Kruskal-Wallis $H$ test, $P<0.05$ for the 14-day exposure). After 3, 7, 10, and 14 days of exposure to lindane, the growth inhibition of earthworms treated with the higher doses (120 and $150 \mathrm{mg} \mathrm{kg}^{-1}$ ) were significantly higher than those for treatments at low and medium concentrations $\left(20,50\right.$, and $\left.80 \mathrm{mg} \mathrm{kg}^{-1}\right)(\mathrm{S}-\mathrm{N}-\mathrm{K}$ test, $P<0.05)$. Furthermore, at day 14, the inhibition in the dose group of $150 \mathrm{mg} \mathrm{kg}^{-1}$ was significantly higher than that in the group of $120 \mathrm{mg} \mathrm{kg}^{-1}$.

During the 14-day exposure period, the growth inhibition for all of the earthworms cultured in the deltamethrin-treated soil (Fig. 1b) were positive and significantly different $(P<0.001)$ from those for the controls. The decreases in weight after the 7- and 10-day exposures to deltamethrin were found statistically to be dose-dependent (ANOVA: $P<0.01$ for the 7 days of exposure; $P<0.05$ for the 10 days of exposure), with a significant difference between the lower ( 5 and $25 \mathrm{mg} \mathrm{kg}^{-1}$ ) and higher dosage groups (100 and $150 \mathrm{mg} \mathrm{kg}^{-1}$ ). In contrast, no significant difference was observed among the various concentrations for days 3 and 14 (ANOVA: $P>0.05$ for 3 days of exposure; Kruskal-Wallis $H$ test: $P>0.05$ for 14 days of exposure).

The growth inhibition for lindane and deltamethrin appeared to be time-dependent, with longer exposure duration resulting in higher inhibition (Figs. 1a and b).

\subsubsection{Subchronic effects}

The growth inhibition for lindane and deltamethrin after exposures of 28 and 42 days are shown in Figs. $2 a$ and b, respectively. The inhibition of the control groups were $-0.82 \%$ and $-0.50 \%$ at days 28 and 42 , respectively, indicating that a slight increase in biomass might have occurred during the experiment. 

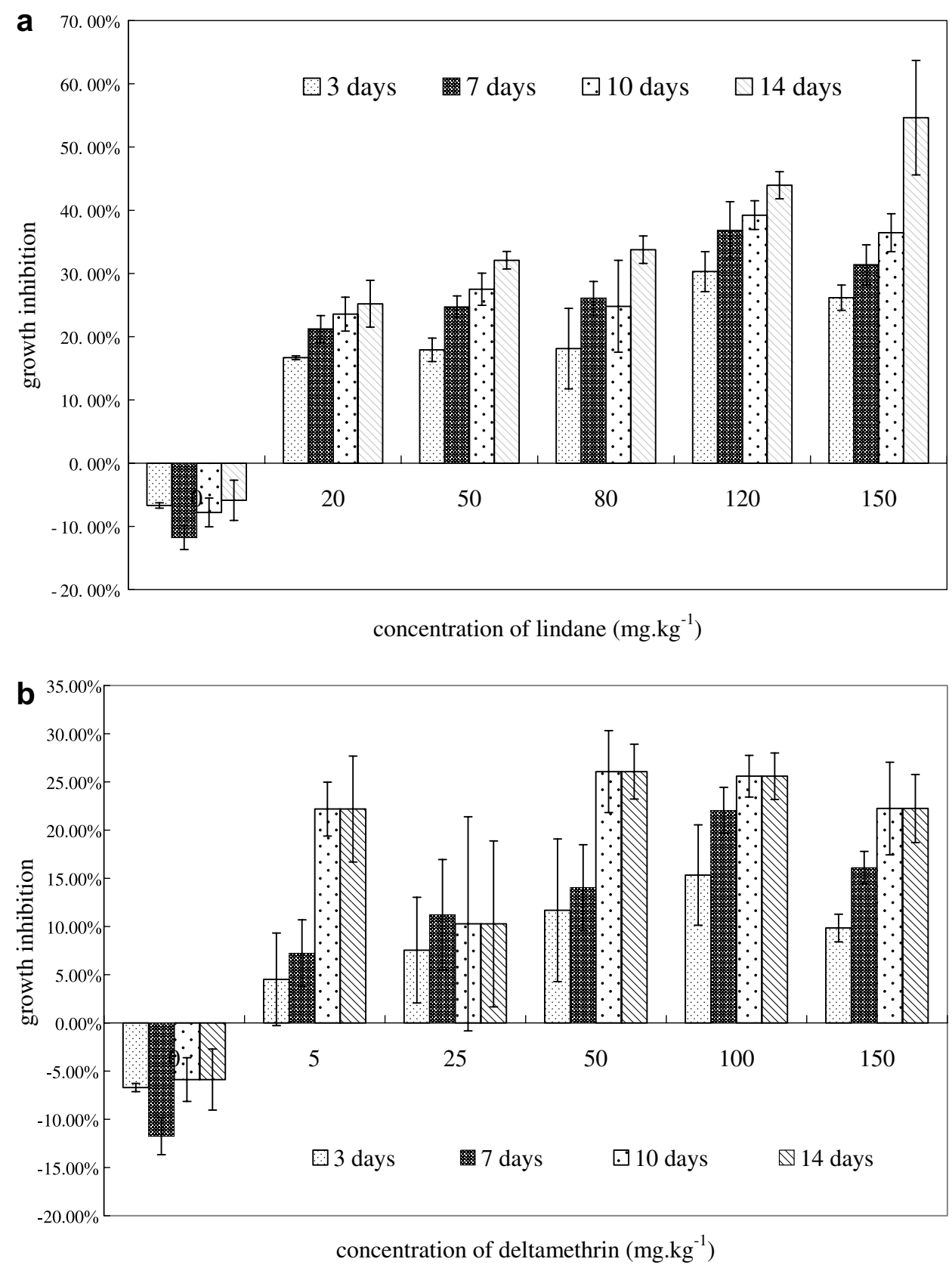

Fig. 1. (a) Growth inhibition in earthworms from acute exposure to lindane. (b) Growth inhibition in earthworms from acute exposure to deltamethrin.

Fig. 2a presents the results of exposure to lindane for 28 and 42 days, with significant differences shown among the various dose groups (ANOVA: $P<0.05$ for 28 days and 42 days) and with significant differences between the high dose $\left(50 \mathrm{mg} \mathrm{kg}^{-1}\right)$ and the lower dosage $\left(1,10\right.$, and $\left.20 \mathrm{mg} \mathrm{kg}^{-1}\right)$ groups. In addition, the growth inhibition for the low dose groups were either very low or negative, each accompanied by a large standard deviation. Results of the $\mathrm{S}-\mathrm{N}-\mathrm{K}$ test showed no statistical difference over control for the low dose groups $(P>0.05)$, suggesting that lindane levels below $20 \mathrm{mg} \mathrm{kg}^{-1}$ have little effect on earthworm growth.

Deltamethrin was found capable of inhibiting earthworm growth, with effects ranging from $16.8 \%$ to $26.6 \%$ after 28 days of exposure and from 19.8 to $36.3 \%$ after
42 days (Fig. 2b). However, the inhibition showed no sign of dose dependency (ANOVA: $P \geqslant 0.05$ for 28 days and 42 days).

\subsection{Cellulase activity}

The data in Figs. 3a and $b$ indicate that the effects of the various doses of lindane and deltamethrin on cellulase activity were significantly different between pesticides and between exposure durations. The Kruskal-Wallis $H$ test showed a statistically significant difference in cellulase activity between the controls and earthworms exposed to lindane at various concentrations for 14 days $(P<0.05)$. Compared to the controls, the cellulase activity in groups 

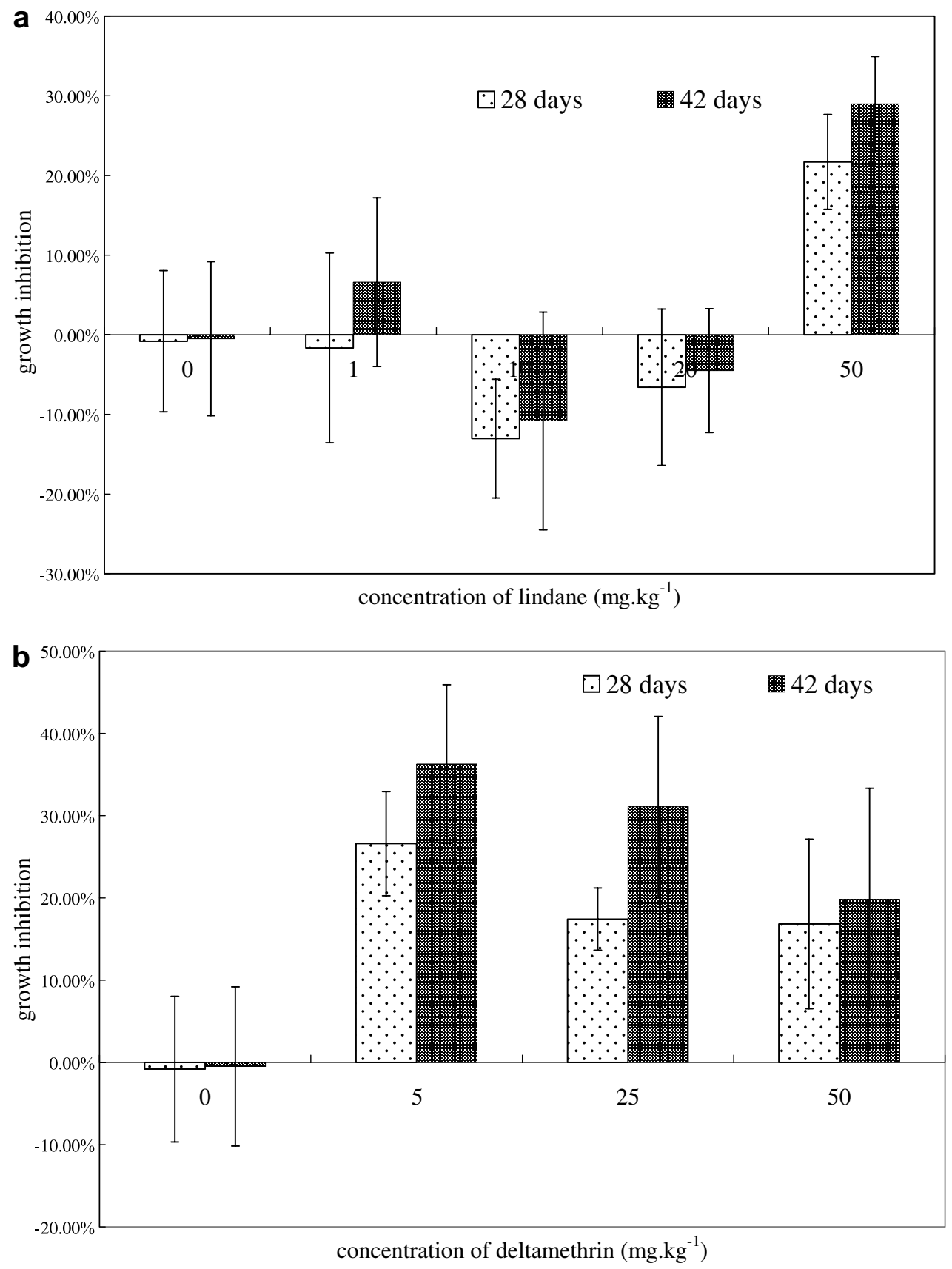

Fig. 2. (a) Growth inhibition in earthworms from subchronic exposure to lindane. (b) Growth inhibition in earthworms from subchronic exposure to deltamethrin.

with the two high doses $\left(120\right.$ and $\left.150 \mathrm{mg} \mathrm{kg}^{-1}\right)$ of lindane increased significantly $(18.7 \%$ and $16.9 \%$, respectively) during the acute test period. At the same time, no significant difference was observed in cellulase activity between earthworms in the control group and those in the low and medium dose groups $\left(20,50\right.$, and $\left.80 \mathrm{mg} \mathrm{kg}^{-1}\right)$.

The cellulase activity was dose-dependent (ANOVA, $P<0.01)$ in groups exposed to low or medium dose of lindane for 42 days (Fig. 3a). Post hoc analysis (with the S-N$\mathrm{K}$ test) indicated that earthworms exposed to the low dose of lindane $\left(20 \mathrm{mg} \mathrm{kg}^{-1}\right)$ for 42 days had a significantly higher cellulase activity than the controls, whereas those exposed to the medium dose $\left(50 \mathrm{mg} \mathrm{kg}^{-1}\right)$ had a similar level of cellulase activity as the controls.

Cellulase activity in earthworms was inhibited in groups exposed to deltamethrin for 14 or 42 days (Fig. 3b). Maximum inhibitions of $24.9 \%$ and $23.6 \%$ were observed in the 5 and $50 \mathrm{mg} \mathrm{kg}^{-1}$ groups, respectively, with a minimum inhibition of $6.9 \%$ in the $100 \mathrm{mg} \mathrm{kg}^{-1}$ group. One-way ANOVA (using the $\mathrm{S}-\mathrm{N}-\mathrm{K}$ test) showed a significant difference between the cellulase activity in the controls and those in earthworms exposed to deltamethrin at various concentrations for 14 days $(P<0.05)$. Fig. $3 b$ also shows little or no inhibition in cellulase activity in earthworms 

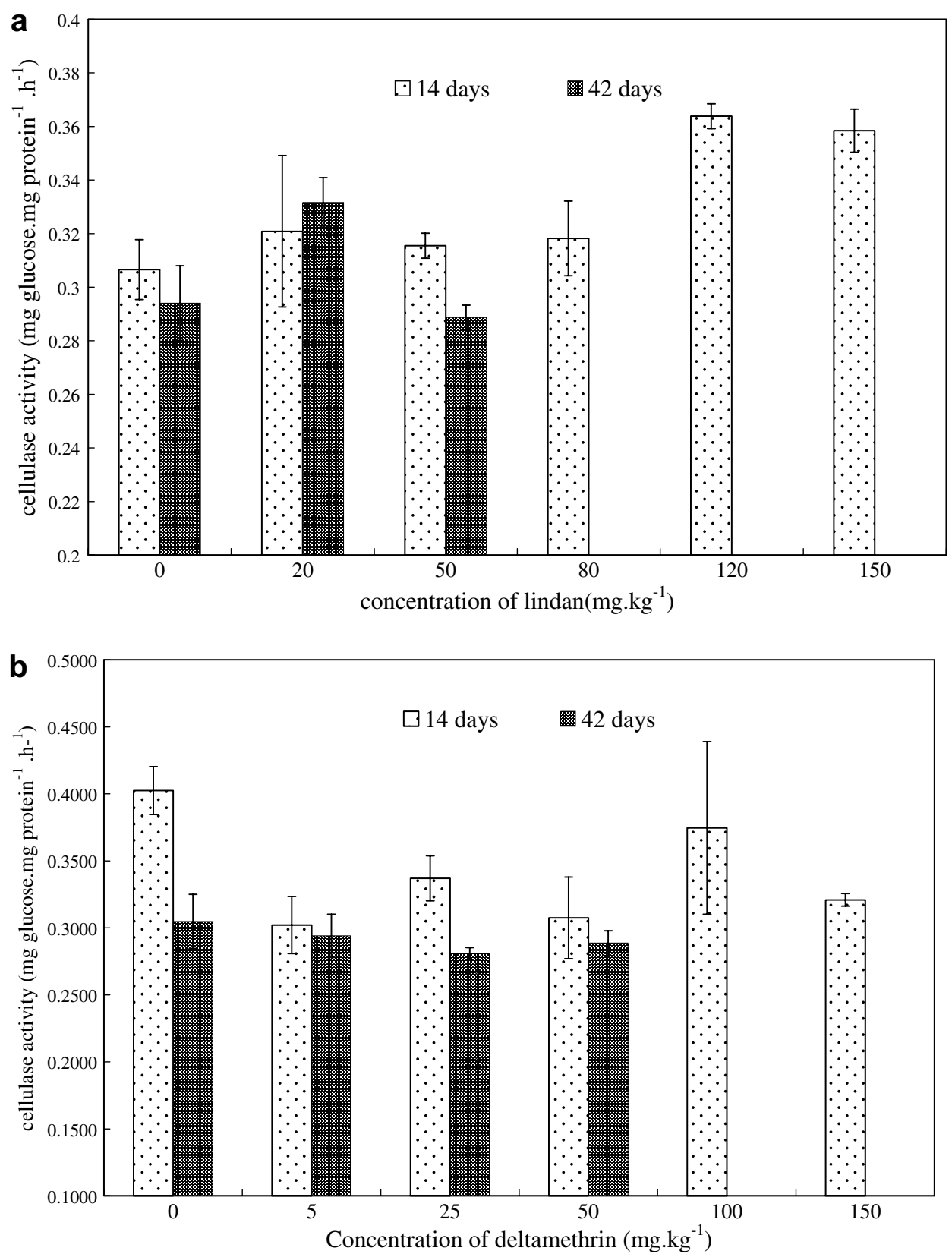

Fig. 3. (a) Cellulase activity in earthworms from acute and subchronic exposures to lindane. (b) Cellulase activity in earthworms from acute and subchronic exposures to deltamethrin.

exposed to the low and medium doses (ANOVA, $P>0.05$ ) after 42 days of exposure to deltamethrin.

\section{Discussion}

\subsection{Mortality and growth inhibition}

Earthworms' mortality can be used as a reliable indicator of environmental pollution. Kokta (1992) reported that pesticides with a $\mathrm{LC}_{50}$ value higher than $1000 \mathrm{mg} \mathrm{kg}^{-1}$ were harmless to earthworms in the field [19]. Data from this study suggested that both lindane and deltamethrin have a lethal effect on earthworms after acute exposure that can lead to a decrease in their population and to changes in the soil ecosystem. These data also indicated that the two pesticides at their lower, standard prescribed doses have very little effect on earthworm mortality.

The calculated $\mathrm{LC}_{50}$ values in this acute toxicity test were not similar to those reported elsewhere in the literature. For example, a $\mathrm{LC}_{50}$ of $70.85 \mathrm{mg} \mathrm{kg}^{-1}$ was reported by Zhang et al. (1985) for a 14-day exposure to lindane using similar incubation methods. Since organic matter is positively correlated with the $\mathrm{LC}_{50}$ value of pesticides [24], the difference observed in the $\mathrm{LC}_{50}$ values here might have been due to the difference in the composition of the organic substances and of the kaolinite clay used in this 
and Zhang's study. Sphagnum peat and kaolinite clay all contain very complex components and requirements for their composition have not been specified in the standard procedures.

Biomass changes can be a good indicator of chemical stress, which may link chemical effects to energy dynamics and ultimately inhibit growth. The slight increase of control earthworms' weight suggested that the soil nutrients were just sufficient to sustain the survival of earthworms, but insufficient to allow for additional growth. The results on growth inhibition treated by the two pesticides were in agreement with those reported on other organic pollutants. For example, a dose-dependent decrease was observed in the growth of $E$. fetida exposed to dieldrin at several sublethal concentrations [25]. A significant growth inhibition on earthworm Lumbricus rubellus was also seen when exposed to PAH pyrene [26].

Both lindane and deltamethrin inhibited earthworm growth, and this is possibly correlated with an earthworm's strategy for natural survival: reducing food intake to avoid the toxins. This strategy is commonly used in earthworms to avoid poisoning not only with heavy metals [27] but also organic chemicals. Similar body adjustments were observed with the isopod Porcellio dilatatus, with reduction of consumption rates when exposed to high doses of endosulfan, and their other feeding parameters (assimilation rates, food assimilation efficiency) were significantly affected, and finally their growth was inhibited [28].

Compared with those of lindane, effects of deltamethrin on the growth of earthworms exhibited different time tendency. This difference might have been due to the difference in the character of the two pesticides. Deltamethrin is not of long persistence, and has comparatively shorter half-life time than lindane in soil. For example, the half life of deltamethrin in glebe soil is 46.5 days, whereas that of lindane is 103.6 days [29]. Also since deltamethrin is fairly rapidly metabolized, bioaccumulation does not occur, the concentrations of deltamethrin in the soil and in the earthworms declined rapidly during the acute test period, no dosedependent inhibition observed on earthworm growth afterwards. Due to lindane's high persistence and bioaccumulation, its remaining residues in the soil and in the earthworms were sufficient to inhibit earthworm growth during all of the exposure periods tested in this study. For example, an experiment revealed that the concentration of lindane in earthworms increased quickly, after 7 days of exposure it reached a peak and holded its value until 28 days, then declined and reached a state of balance at 42 days again [30].

\subsection{Cellulase activity}

Occurrence of cellulase in the earthworms' gut indicates their role in the decomposition of plant litter and other cellulosic materials. Cellulase poses great importance to $E$. fetida, e.g. its activity was 7 -fold greater than that in the gut of Metaphire guillelmi [17]. This study shows that acute exposure to deltamethrin reduced cellulase activity, while exposures to lindane increased it; this indicates the harmful effect of deltamethrin and the inducing effects of lindane on the biochemical metabolism of earthworms.

It is unclear why lindane increased the cellulase activity in earthworms whereas deltamethrin exerted the opposite effect. The biochemical mechanisms leading to such inconsistency apparently need to be further investigated. Nonetheless, it is plausible that the different effects exerted on the cellulase activity could be due to both the differences in the chemical structure and in the functional group between the two pesticides. Deltamethrin is also relatively short-lived in the environment and rapidly metabolized or excreted inside an organism. These biological differences may help to explain the inhibitory effects on the cellulase activity observed in the acute exposure period and the lack of such effects in the subchronic exposure period. The observed recovery of cellulase activity might have been due to a decline in deltamethrin concentration and/or possible adaptation on the part of earthworms to the remaining residues through enhanced metabolism. It is also possible that the deltamethrin absorbed by earthworms was rapidly hydrolyzed by hydrolytic fermentation inside these organisms, thus allowing some recovery from the inhibition of cellulase activity.

\subsection{Conclusion}

Both lindane and deltamethrin were toxic or even lethal to earthworms under acute exposure. The toxic potential of lindane was greater than that of deltamethrin at day 14 of exposure.

Lindane exerted significant effects on earthworm growth and cellulase activity at both acute and subchronic exposures, whereas deltamethrin's effects occurred only during the acute exposure period.

These results suggest that changes in biomass and cellulase activity during subtle exposure periods may be more sensitive parameters than $\mathrm{LC}_{50}$ in order to assess the extent of injury caused by pesticides, since they provide early warning responses at sublethal doses and are close related to the naturally occurring ones in the environment.

\section{Acknowledgments}

This work was supported by National Natural Science Foundation of China (No. 40601089). The authors thank Prof. Sun Zhenjun of the China Agricultural University for providing the earthworms and his support in the toxicity tests. We thank Prof. James Douglas and Prof. Elizabeth Douglas of the Mac Univesity, and Prof. Richard W. Dawson of the China Agricultural University for reviewing the manuscript and helpful suggestions. We acknowledge the anonymous referees for their constructive comments. 


\section{References}

[1] S.P. Bradbury, J.R. Coats, Toxickinetics and toxicodynamics of pyrethroid insecticides in fish, Environmental Toxicology and Chemistry 8 (1989) $373-380$.

[2] OECD, Guidelines for testing of chemicals. Test 207: Earthworm Acute Toxicity Tests. Organization for Economic Co-operation and Development (OECD), Paris, 1984.

[3] C.A. Menzie, D.E. Burmaster, J.S. Freshman, C.A. Callahan, Assessment of methods for estimating ecological risk in the terrestrial component: a case study at the Baird and McGuire superfund site in Holbrook, Massachusetts, Environmental Toxicology and Chemistry 11 (1992) 245-260.

[4] S.R. Stürzenbaum, P. Kille, A.J. Morgan, Heavy metal-induced molecular responses in the earthworm, Lumbricus rubellus genetic fingerprinting by directed differential display, Applied Soil Ecology 9 (1998) 495-500.

[5] R.W. Parmelee, M.H. Beare, W. Cheng, P.F. Hendrix, S.J. Rider, D.A. Crossley Jr., D.C. Coleman, Earthworms and enchytraeids in conventional and no-tillage agro-ecosystems: a biocide approach to assess their role in organic matter breakdown, Biology and Fertility of Soils 10 (1990) $1-10$.

[6] J.E. Morgan, A.J. Morgan, The accumulation of metals $(\mathrm{Cd}, \mathrm{Cu}, \mathrm{Pb}$, $\mathrm{Zn}$ and $\mathrm{Ca}$ ) by two ecologically contrasting earthworm species (Lumbricus rubellus and Aporrectodea caliginosa): implications for ecotoxicological testing, Applied Soil Ecology 13 (1999) 9-20.

[7] B. Halliwell, J.M. Gutteridge, Role of free radicals and catalytic metal ions in human disease: an overview, Methods in Enzymology 186 (1990) 1-85.

[8] J. Stenersen, Action of pesticides on earthworms. Part-I: the toxicity of cholinesterase inhibiting insecticides to earthworms as evaluated by laboratory tests, Pesticide Science 10 (1979) 66-71.

[9] C.D. Drewes, E.P. Vining, In vivo neurotoxic effects of dieldrin on giant nerve fibers and escape reflex functioning in the earthworm Eisenia fetida, Pesticide Biochemistry and Physiology 22 (1984) 93104.

[10] S.M.M. Ismail, Y.M. Ahmed, Y.Y. Mosleh, M.T. Ahmed, The activities of some proteins and protein related enzymes of earthworms as biomarkers for atrazine exposure, Toxicological and Environmental Chemistry 63 (1997) 141-148.

[11] S. Loureiro, A.M.V.M. Soares, A.J.A. Nogueira, Terrestrial avoidance behavior tests as screening tool to assess soil contamination, Environmental Pollution 138 (2005) 121-131.

[12] L.H. Booth, V. Heppelthwaite, A. McGlinchy, The effect of environmental parameters on growth, cholinesterase activity and glutathione S-transferase activity in the earthworm (Aporrectodea caliginosa), Biomarkers 5 (2000) 46-55.

[13] M. Saint-Denis, F. Labrot, J.F. Narbonne, D. Ribera, Glutathione, glutathione-related enzymes, and catalase in the earthworm Eisenia fetida andrei, Archives of Environmental contamination and Toxicology 35 (1998) 602-614.

[14] M. Saint-Denis, J.F. Narbonne, C. Arnaud, E. Thybaud, D. Ribera, Biochemical responses of earthworm Eisenia fetida Andrei exposed to contaminated artificial soil: effects of benzo(a)pyrene, Soil Biology and Biochemistry 31 (1999) 1837-1846.

[15] P. Scaps, C. Grelle, M. Descamps, Cadmium and lead accumulation in the earthworm Eisenia fetida (Savigny) and its impact on cholinesterase and metabolic pathway enzyme activity, Comparative Biochemistry and Physiology C, Toxicology Pharmacology 116 (1997) 233-238.

[16] B.G. Zhang, C. Rouland, C. Lattaud, P. Lavelle, Activity and origin of digestive enzymes in gut of the tropical earthworm (Pontoscolex corethrurus), European Journal of Soil Biology 29 (1993) 7-11.

[17] B.G. Zhang, G.T. Li, T.S. Shen, J.K. Wang, Z. Sun, Changes in microbial biomass $\mathrm{C}, \mathrm{N}$, and $\mathrm{P}$ and enzyme activities in soil incubated with the earthworms Metaphire guillelmi or Eisenia fetida, Soil Biology \& Biochemistry 32 (2000) 2055-2062.

[18] Y. Luo, Y. Zang, Y. Zhong, Z.M. Kong, Toxicological study of two novel pesticides on earthworm Eisenia foetida, Chemosphere 39 (1999) 2347-2356.

[19] C. Kokta, A laboratory test on sublethal effects of pesticides on Eisenia fetida, in: H. Becker, P.J. Edwards, P.W. Greig-Smith, F. Heimbach (Eds.), Ecotoxicology of Earthworms, Intersept Press, Andover, Hants, 1992, pp. 55-62.

[20] P.C. Mishra, M.C. Dash, Digestive enzymes of some earthworms, Experimenta 36 (1980) 1156-1157.

[21] T.K. Ghose, Measurement of cellulase activity, Pure and Applied Chemistry 59 (1987) 257.

[22] G.L. Miller, Use of dinitrosalicylic acid reagent for determination of reducing sugar, Analytical Chemistry 31 (1969) 426-428.

[23] O.H. Lowry, N.J. Rosebrough, A.L. Farr, R.J. Randall, Protein measurement with folin-phenol reagent, Journal of Biological Chemistry 193 (1951) 265-275.

[24] R.W. Zhang, Z.X. Li, Q.Y. Bai, D.J. Cai, Detection of the toxicity of pesticides on earthworms by standard method, Acta Scientiae Circumstantiae 5 (3) (1985) 327-333 (in Chinese, with English abstract).

[25] A.J. Reinecke, J.M. Venter, Influence of dieldrin on the reproduction of the earthworm Eisenia fetida (Oligochaeta), Biology and Fertility of Soils 1 (1985) 39-44.

[26] P.J. Brown, S.M. Long, D.J. Spurgeon, C. Svendsen, P.K. Hankard, Toxicological and biochemical responses of the earthworm Lumbricus rubellus to pyrene, a non-carcinogenic polycyclic aromatic hydrocarbon, Chemosphere 57 (2004) 1675-1681.

[27] L.A. Burrows, C.A. Edwards, The use of integrated soil microcosms to predict effects of pesticides on soil ecosystems, European Journal of Soil Biology 38 (2002) 245-249.

[28] S. Ribeiro, J.P. Souza, A.J.A. Nogueira, A.M.V.M. Soares, Effect of endosulfan and parathion on energy reserves and physiological parameters of the terrestrial isopod Porcellio dilatatus Ecotoxicol, Environmental Safety 49 (2001) 131-138.

[29] D.D. Zhang, X.H. Zhang, Pesticide Pollution and Control, Chemical Industry Press, Beijing, 2001, p. 88 (in Chinese).

[30] Y.S. Lin, R.Z. Gong, Z.L. Zhu, Pesticide and Eco-environment Protection, Chemical Industry Press, Beijing, 2000, pp. 14-15 (in Chinese). 